\title{
CONSIDERAÇÕES SOBRE A EXIGIBILIDADE JUDICIAL DOS DIREITOS SOCIAIS EM UM ESTADO DEMOCRÁTICO DE DIREITO*
}

\author{
Márcio Ricardo Staffen * \\ Octaviano Langer ${ }^{* * *}$
}

\begin{abstract}
SUMÁRIO: introdução 1. Direitos fundamentais: noções introdutórias 2. Direitos sociais como direitos fundamentais 3. O papel do Estado 4. A exigibilidade judicial 5. Jurisdição democrática e acesso à justiça como resposta jurisdicional às questões sociais considerações finais referência das fontes citadas
\end{abstract}

RESUMO: O presente artigo científico propõe-se a apresentar rápidas considerações sobre a exigibilidade judicial dos direitos sociais em um Estado Democrático de Direito. Para tanto, inicia-se o estudo pela exposição de algumas noções fundamentais acerca da gênese histórica, conceito e processo de generalização dos Direitos Fundamentais. Ato contínuo, o fenômeno da judicialização dos direitos sociais é analisado sob uma ótica de possibilidade e adequação do Poder Judiciário como lócus democrático para a realização dos destes direitos. Utilizou-se, para o desenvolvimento desta presente pesquisa, o método indutivo, operacionalizado pelas técnicas de conceitos operacionais e da pesquisa bibliográfica.

Palavras-chave: Direitos Sociais; Exigibilidade Judicial; Estado Democrático de Direito.

\begin{abstract}
This research paper proposes to present brief remarks on the legal enforceability of social rights in a democratic state. To this end, the study begins by presenting some basic notions about the historical genesis, concept and process of generalization of Fundamental Rights. Immediately thereafter, the phenomenon of legalization of social rights is analyzed from a perspective of possibility and suitability of the Judiciary as a locus for the realization of democratic rights of these. It was used for the development of this research, the inductive method, operated by the techniques of operational concepts and literature.
\end{abstract}

Keywords: Social Rights, Judicial Enforceability; Democratic state.

\section{INTRODUÇÃO}

O presente artigo propõe-se a analisar a exigibilidade judicial dos direitos sociais em um Estado Democrático de Direito. Preliminarmente faz-se imperioso advertir que a matéria é de extrema relevância no cenário mundial, por sua vez a tratativa do tema é assunto recorrente. Assim, este trabalho não objetiva esgotar o debate, mas trazer novos argumentos no intuito de reforçar a possibilidade de se exigir os direitos sociais via jurisdição democrática,

\footnotetext{
* Para Claudia Anderman, pela constante e fraterna presença acadêmica.

** Bacharel em Direito pela Universidade do Vale do Itajaí - UNIVALI. Mestrando em Ciência Jurídica pela Universidade do Vale do Itajaí - UNIVALI, linha de pesquisa Principiologia, Constitucionalismo e Produção do Direito. Bolsista CAPES. Professor no Curso de Graduação em Direito (Direito das Coisas). Advogado.

*** Bacharel em Direito pela Universidade Federal de Santa Catarina - UFSC. Especialista em Direito Processual pela Universidade do Extremo Sul Catarinense - UNESC. Doutorando em Direito pela Universidad de Buenos Aires - UBA. Mestrando em Ciência Jurídica pela Universidade do Vale do Itajaí - UNIVALI, linha de pesquisa Principiologia, Constitucionalismo e Produção do Direito.
} 
refutando para tanto os principais argumentos sonegadores ou redutores desta garantia de cidadania.

A busca do processo judicial como solução para problemas sociais e demandas populares traz consigo a dúvida quanto à possibilidade de o Poder Judiciário atuar nestas áreas, quanto à qualidade das respostas oriundas dos tribunais, bem como sobre a legitimidade de uma atividade judicial voltada para políticas públicas e inovações de toda ordem no mundo jurídico.

É certo que inércias legislativas e executivas não podem mais ser aceitas nesta quadra da história, especialmente pela extensão positivação de direitos fundamentais de todas as gamas no texto constitucional. Não há mais de se compreender estas normas fundamentais como mero programa de intenções, mas dando-lhes normatividade plena e se exigindo do Estado o seu devido comprimento, ainda que tal tarefa envolva a realização de prestações positivas.

Desta feita, a atividade jurisdicional ligada às questões sociais adquire legitimidade a partir da visão constitucional de que o processo judicial pode ser uma resposta democrática para a realização de direitos fundamentais negligenciados por outros órgãos e poderes. Daí a construção de um conceito de Jurisdição Democrática, baseada em uma atuação próxima da política e dos interesses da sociedade.

E esta atuação jurisdicional democrática, aliada a um efetivo acesso à justiça trará respostas úteis e necessárias socialmente, afastando de uma vez as críticas acerca do limites da atuação judicial, e legitimando a utilização de instrumentos processais e jurídicos para a maximização de direitos e concretização de políticas voltadas para o social.

\section{DIREITOS FUNDAMENTAIS: NOÇÕES INTRODUTÓRIAS}

Antes, porém, da exposição acerca dos direitos sociais é de grandiosa relevância resgatar sumariamente os antecedentes históricos, sociais e jurídicos dos Direitos Fundamentais. Sem os fundamentos dos Direitos Fundamentais jamais se obterá o resultado pretendido com este estudo.

Ao longo dos períodos históricos os bens socialmente considerados de maior relevância foram incorporados em documentos escritos que buscaram estabelecer limites à atuação estatal declarando direitos e assegurando medidas garantidoras das disposições declaratórias ${ }^{1}$. Ilustra este cenário, por exemplo, a Carta outorgada pelo Rei Alfonso IX às cortes de Leon, em 1188, e a imposição da Magna Charta Libertatum, em 1215, e demais declarações similares e em um período cronológico próximo. Contudo, pelo fato de tais documentos fornecerem privilégios à nobreza e alto clero, somente, não é suficiente para

\footnotetext{
${ }^{1}$ STAFFEN, Márcio Ricardo; CADEMARTORI, Daniela Mesquita Leutchuk de. A função democrática do princípio do contraditório no âmbito do processo administrativo disciplinar: aproximações entre Elio Fazzalari e Jürgen Habermas. Revista Brasileira de Direitos Fundamentais \& Justiça - Revista do Programa de Pós-Graduação Mestrado e Doutorado em Direito da PUC/RS. Porto Alegre, a. IV, n. 12, p. 235-246, jul/set. 2010.
} 
identificar nas suas assinaturas o advento dos Direitos Fundamentais, afinal uma das características básicas dos Direitos Fundamentais é sua generalização.

Na lavra de Peces-Barba Martínez a gênese dos Direitos Fundamentais remonta ao trânsito para a Modernidade ${ }^{2}$. Não se pode falar propriamente de Direitos Fundamentais até a Modernidade. Somente com o câmbio na situação econômica e social, com o surgimento de um sistema econômico que desembocara no capitalismo, com o auge de uma classe social progressiva e em ascensão (a burguesia), a mutação do poder político com a aparição do Estado, como poder racional, centralizador e burocrático; a evolução da mentalidade fomentada pelos humanistas e pela Reforma, com o progresso do individualismo, do racionalismo, do naturalismo e do processo de secularização; o movimento da ciência e o novo sentido de Direito são signos decisivos do advento dos Direitos Fundamentais. ${ }^{3}$

Bem verdade que valores caros aos Direitos Fundamentais como dignidade humana, liberdade, igualdade e fraternidade são empregados em períodos anteriores da História universal. Apenas como rol exemplificativo vislumbra-se estes arquétipos no pensamento de Platão, Aristóteles, Cristo, Cícero, Tomás de Aquino..., contudo, é a falta de um complexo de situações sociais, políticas e jurídicas receptivas à ideia de Direitos Fundamentais que impedem o reconhecimento do natalício de tal classe de Direitos num período anterior ao trânsito para a Modernidade. Nos dizeres de Pérez Luño, ainda que este utilize a categoria Direitos Humanos, os Direitos Fundamentais nascem com a Modernidade, inspirados nas revoluções liberais do século XVIII. ${ }^{4}$

Feita esta localização cronológica do surgimento dos Direitos Fundamentais, ainda que rapidamente, diga-se de passagem, faz-se imperioso conceituar a categoria Direitos Fundamentais. Num cenário conceitual em que se discutem classificações como Direitos Humanos, Direitos Naturais, Direitos Públicos Subjetivos, Liberdades Públicas e Direitos Morais a preferência pela alcunha Direitos Fundamentais se justifica por ser mais precisa que a expressão Direitos Humanos, pois carece e escapa das ambigüidades que esta supõe; pode suportar as duas dimensões em que aparecem os Direitos Humanos, sem incorrer no reducionismo jusnaturalista ou positivista, pois expressam tanto uma moralidade básica como uma juridicidade essencial; é mais adequada que os termos Direitos Naturais ou Direitos Morais que desdenha sua faceta jurídicopositiva; e, é mais apropriada que a noção de Direitos Públicos Subjetivos ou

2 No sentido histórico, determina Nicola Abbagnano, quando se fala em filosofia moderna e em Modernidade, indica-se o período da história ocidental que começa depois do Renascimento, a partir do século XVII. ABBAGNANO, Nicola. Dicionário de filosofia. 2. ed. Trad. Alfredo de Bosi. São Paulo: Mestre Jou, 1962, p. 679.

${ }^{3}$ PECES-BARBA MARTÍNEZ, Gregorio. La diacronia del fundamento y del concepto de los derechos: el tiempo de la historia. In: Curso de derechos fundamentales. Teoría general. Madrid: Universidad Carlos III de Madrid, 1995, p. 113-114.

4 PÉREZ LUÑO, Antonio-Enrique. La universalidad de los derechos humanos. In: La universalidad de los derechos humanos y Estado constitucional. Bogotá: Universidad Externado de Colombia, 2002, p. 23. 


\section{Liberdades Públicas que podem preterir a dimensão moral existente no conceito de Direitos Fundamentais. ${ }^{56}$}

Ainda no magistério de Peces-Barba Martínez, os Direitos Fundamentais, enquanto conceito integral ${ }^{7}$ são:

Una pretensión moral justificada, tendente a facilitar la autonomía y la independencia personal, enraizada en las ideas de libertad e igualdad, con los matices que aportan conceptos como solidariedad y seguridad jurídica, y construida por la reflexión racional en la historia del mundo moderno, con las aportaciones sucesivas e integradas de la filosofía moral y política liberal, democrática y socialista. [...]. Un subsistema dentro del sistema jurídico, el Derecho de los derechos fundamentales, lo que supone que la pretensión moral justificada sea técnicamente incorporable a una norma, que pueda obligar a unos destinatarios correlativos de las obligaciones jurídicas que se desprenden para que el derecho sea efectivo, que sea susceptible de garantía o protección judicial, y, por supuesto que se pueda atribuir como derecho subjetivo, libertad, potestad o inmunidad a unos titulares concretos. [...]. En tercer lugar, los derechos fundamentales son una realidad social, es decir, actuante en la vida social, y por tanto condicionados en su existencia por factores extrajurídicos de carácter social, económico o cultural que favorecen, dificultan o impiden su efectividad. ${ }^{8}$

Ante o exposto, o conceito formulado por Peces-Barba permite compreender os Direitos Fundamentais como um conceito histórico, portanto, aberto à incorporação de novos direitos moralmente justificáveis, aptos a serem positivados e condizentes com a realidade social local. Ou como prefere Ferrajoli, a história dos Direitos Fundamentais é uma história não teórica, sendo

${ }^{5}$ PECES-BARBA MARTÍNEZ, Gregorio. La diacronia del fundamento y del concepto de los derechos: el tiempo de la historia. p. 36-38.

${ }^{6}$ Seguindo também o ensinamento de Marcos Leite Garcia, enquanto utilizadas para exposições teóricas, podem ser usadas as três expressões: direitos humanos; direitos do homem e direitos fundamentais, muito embora as duas primeiras expressões sejam mais empregadas em tratados internacionais, e a terceira para representar os direitos positivados em âmbito estatal. Por questões de conveniência, utilizarse-á neste artigo a expressão Direitos Fundamentais. In: GARCIA, Marcos Leite. Efetividade dos Direitos Fundamentais: notas a partir da visão integral do conceito segundo Gregorio Peces-Barba. In: VALLE, Juliano Keller do; MARCELINO JR., Julio Cesar. Reflexões da Pós-Modernidade: Estado, Direito e Constituição. Florianópolis: Conceito Editorial, 2008. p. 190-191.

7 "El modelo integral de derechos humanos, que rechaza los reduccionismos, supone aceptar una moralidad de la libertad y de la igualdad que se va formando en la historia del mundo moderno, con aportaciones liberales, democráticas y socialistas, que se pueden ordenar en un modelo racional, aunque partiendo de su ineludible dimensión histórica. Supone aceptar que la eficiencia social de esas pretensiones morales necesita de su incorporación al Derecho positivo. Supone igualmente, que la relación entre moralidad y Derecho positivo necesita de la mediación de un poder político que asuma esos valores éticos como valores políticos, y los incorpore a su Ordenamiento como valores del Derecho." PECES-BARBA MARTÍNEZ, Gregorio. Problemas generales. In: derechos fundamentales. Teoría general. Madrid: Universidad Carlos III de Madrid: 1995, p. 57.

${ }^{8}$ PECES-BARBA MARTÍNEZ, Gregorio. La diacronia del fundamento y del concepto de los derechos: el tiempo de la historia. p. 109-112. 
social e política, haja vista que nenhum destes direitos caíram do céu, sendo que todos foram conquistados por movimentos revolucionários ${ }^{9}$. Destarte, face esta constante possibilidade de evolução diversos doutrinadores atribuem aos Direitos Fundamentais a subdivisão em dimensões, gerações e demais alcunhas, no intuito de caracterizar particularidades específicas determinantes.

\section{DIREITOS SOCIAIS COMO DIREITOS FUNDAMENTAIS}

Em termos práticos, contudo, a igualdade consagrada na divisa dos revolucionários com o decurso do tempo mostrou-se vinculada exclusivamente ao aspecto jurídico-formal. Grosso modo, com as revoluções liberais e a instituição de Estados mínimos, salvo à burguesia, nada mudara aos vassalos do ancien régime. Alterou-se somente o critério determinante das relações, deixando a cena o paradigma nobiliário para dar lugar às leis de mercado. Nos dizeres de Delfim Neto a sociedade humana tornou-se um organismo, e o funcionamento da economia - o jogo das forças da oferta e da procura - moldou e contratou o processo de interação social. ${ }^{10}$

Segundo Trindade ${ }^{11}$, os efeitos comuns da Restauração e da Revolução Industrial instauraram na Europa, na primeira metade do século XIX, a primeira grande crise dos Direitos Humanos. A seu ver ela se configura de duas maneiras, institucional, devido à resistência combinada da reação monárquica e dos liberais em estender os direitos políticos aos trabalhadores. E com o agravamento no plano econômico-social, pois, além da convergência dessas duas forças no propósito de manter a igualdade em estado de minimalismo jurídico-formal (recusa em ampliá-la ao campo social), a Revolução Industrial havia piorado substancialmente as condições de vida dos trabalhadores.

Neste diapasão, tem início, ainda que timidamente, um processo de generalização dos Direitos Fundamentais, os quais passam a receber a adjetivação de Direitos Sociais. Utilizando-se de alguns trechos do discurso revolucionário redigido pela burguesia na construção de uma plataforma interessada em mobilizar o entusiasmo e a vitalidade do povo, como o fato de que todos nascem e são criados iguais, consignado, inclusive, na Declaração de Independência estadunidense, as minorias organizadas passam a reclamar por igualdade substancial devidamente elevada à condição de direitos e garantias.

Aduz Peces-Barba Martínez ${ }^{12}$ que a generalização materializa um progressivo, mesmo que não definitivo, ajuste entre as afirmações de que os

${ }^{9}$ CARBONELL, Miguel. La garantía de los derechos sociales en la teoría de Luigi Ferrajoli. In:

SALAZAR, Pedro. Garantismo. Estudios sobre el pensamiento jurídico de Luigi Ferrajoli. Madrid: Trotta, 2005, p. 172.

${ }^{10}$ DELFIM NETO, Antonio. A criação de alternativas. Folha de São Paulo. São Paulo, 21 nov. 1999, p. 09.

${ }^{11}$ TRINDADE, José Damião de Lima. A história social dos direitos humanos. São Paulo: Peirópolis, 2002, p. 88.

${ }^{12}$ PECES-BARBA MARTÍNEZ, Gregorio. La diacronia del fundamento y del concepto de los derechos: el tiempo de la historia. p. 160-161. De igual forma: GARCIA, Marcos Leite. Direitos fundamentais e 
direitos são naturais, isto é, correspondem a todos os seres humanos, além de não se restringir ao gozo de uma classe específica, tal como a burguesia. Por sua vez, esta etapa inaugura os Direitos Fundamentais como categoria histórica, expressão de todo o gênero humano, uma formulação geral e abstrata, válida para todos os tempos.

Destarte, este processo de generalização possui três grandes dimensões. $\mathrm{Na}$ acepção de Peces-Barba Martínez ${ }^{13}$ reflete a possibilidade de uma participação política igualitária; que inclui a possibilidade de participação das classes trabalhadoras para assegurar a solidariedade e a igualdade; e, por fim, a desfundamentalização do direito à propriedade.

Esta ebulição de ações e reações possibilita a passagem do Estado Liberal para o Estado Social. Segundo Carbonell o surgimento do Estado Social advém de algumas condições, a saber: a) o indivíduo é incapaz de se satisfazer por si próprio, ou com a ajuda de seu entorno social mais próximo, suas necessidades; b) surgem riscos sociais que não podem ser enfrentados pelas vias tradicionais, fundamentadas na responsabilidade individual; c) se desenvolve a convicção social de que o Estado deve assumir a responsabilidade de assegurar a todos os indivíduos um mínimo de bem-estar, se o Estado não cumprir com essa obrigação, colocará em xeque sua legitimidade. ${ }^{14}$

Ressalte-se que, muito embora, os direitos sociais preencham todas as qualidades estipuladas por Peces-Barba Martínez para caracterizarem Direitos Fundamentais; sua gênese refletir uma situação de inconformismo de indivíduos indefesos e oprimidos, assim como era a burguesia pré-Revolução francesa, é forte a investida contra a fixação dos direitos sociais como Direitos Fundamentais. Entre posições reducionistas ou negadores ${ }^{15}$ transitam conservadores, o pontificado e (neo)liberais que miram tão somente a manutenção de privilégios presentes e/ou de outrora, aleijado completamente os ideais maiores dos Direitos Fundamentais. Dentre a teoria persistente mais forte, o reducionismo (neo)liberal argüi, equivocadamente (conforme se demonstrará a seguir), que serão Direitos Fundamentais, exclusivamente, aqueles que exijam do Estado uma postura negativa. ${ }^{16}$

Em suma, seguindo os apontamentos de Abramovich e Courtis ${ }^{17}$, é preciso mensurar que direitos econômicos, sociais e culturais assim como os direitos liberais, civis e políticos são Direitos Fundamentais. Qualquer tentativa

transnacionalidade: um estudo preliminar. In: CRUZ, Paulo Márcio; STELZER, Joana. Direito e transnacionalidade. Curitiba: Juruá, 2009, p. 178.

${ }^{13}$ PECES-BARBA MARTÍNEZ, Gregorio. La diacronia del fundamento y del concepto de los derechos: el tiempo de la historia. p. 168.

${ }^{14}$ CARBONELL, Miguel. La garantía de los derechos sociales en la teoría de Luigi Ferrajoli. p. 175.

${ }^{15}$ PECES-BARBA MARTÍNEZ, Gregorio. Problemas generales. p. 39-98.

${ }^{16}$ STAFFEN, Márcio Ricardo. Entre a liberdade de contratar e a maximização de riquezas o direito do trabalho. Revista Eletrônica Investidura. Florianópolis, a. II, n. IX, p. 40-55, nov/dez. 2009.

17 ABRAMOVICH, Victor; COURTIS, Christian. Los derechos sociales como derechos exigibles. Madrid: Trotta, 2002, p. 19. 
de negação ou redução tipifica um golpe. A distinção reside mais em diferenças de grau do que substanciais.

\section{O PAPEL DO ESTADO}

O paradigma liberal concebeu o Estado de direito como circunscrito somente por proibições, edificado sobre a flâmula da garantia dos indivíduos não serem tolhidos de suas liberdades. Conforme atesta Ferrajoli, "las garantías liberales o negativas consisten únicamente en deberes públicos negativos o de no hacer - de dejar vivir y de dejar hacer - que tienen por contenido prestaciones negativas o no prestaciones" $" 18$. Desta forma, equivocadamente, os Direitos Fundamentais ficaram limitados tão somente à natureza abstencionista do Estado. Qualquer direito que reclamasse uma ação interventiva não seria Direito Fundamental.

Contudo, o individualismo e o abstencionismo ou neutralismo do Estado Liberal geraram imensas injustiças, demonstradas abertamente pelos movimentos sociais, sedentos em realizar a justiça social, corretiva dos absurdos liberais. De igual sorte, a progressiva vulnerabilidade dos indivíduos e a necessidade de socorro dos riscos eram e continuam sendo problemas que não podem mais ser deixados a cargo das obras de caridade privada ou de filantropia religiosa.

Nos dizeres de Carbonell esta é uma das transformações que em maior grau vão incidir sobre a teoria dos Direitos Fundamentais e sobre os processos de legitimação dos poderes públicos em relação com estes direitos. Assim, no modelo de Estado Social os poderes públicos deixam de ser percebidos como antagônicos aos Direitos Fundamentais e começam uma função de promoção destes direitos, sobre tudo os de caráter social ${ }^{19}$. Ademais, o modelo de direito social não é um modelo que substitui por completo o modelo de direito privado clássico, de matriz liberal, trata-se de um modelo corretivo dos excessos e disfunções do paradigma liberal. ${ }^{20}$

Do ponto de vista do senso comum teórico, toda esta trajetória de atuação do Estado ficou sintetizada na noção de que o Estado Liberal estava limitado, exclusivamente, a uma postura não-intervencionista enquanto o Estado Social deveria atuar positivamente. Contudo, pela lavra de Abramovich e Courtis, identificar um direito como civil e político, ou social, baseado simplesmente nas obrigações delas decorrentes, "és simplemente el resultado de una decisión convencional, más o menos arbitraria"21. Por exemplo: direitos

${ }^{18}$ FERRAJOLI, Luigi. Derecho y razón. Teoría del garantismo penal. 2. ed. Trad. Perfecto Andrés Ibáñez. Madrid: Trotta, 2004, p. 860.

${ }^{19}$ CARBONELL, Miguel. La garantía de los derechos sociales en la teoría de Luigi Ferrajoli. p. 178-179.

${ }^{20}$ ABRAMOVICH, Victor; COURTIS, Christian. Los derechos sociales como derechos exigibles. p. 52.

${ }^{21}$ ABRAMOVICH, Victor; COURTIS, Christian. Los derechos sociales como derechos exigibles. p. 27. 
tipicamente civis e políticos, como o devido processo legal, o acesso à justiça, o direito de eleger e ser eleito, bem como a manutenção de um corpo policial supõe a criação, por parte do Estado, de uma série de condições e instituições para a consolidação destes direitos. Estas são nitidamente obrigações positivas, que requerem parcela significativa de recursos públicos, mesmo que vinculadas a direitos negativos. Ao reverso, os direitos sociais também supõem uma parcela de não-fazer, a saber: o direito à saúde implica na obrigação de não danificar a saúde, o direito ao meio ambiente, uma vedação à sua destruição.

\begin{abstract}
Contrariamente a lo que podría parecer, también los derechos de libertad requieren, para poder tener relevancia práctica y no quedar como buenos deseos contenidos solamente en el texto de las constituciones, de actuaciones positivas del Estado, las cuales conllevan en no pocas ocasiones importantes erogaciones económicas; conjugan por tanto obligaciones de no hacer y obligaciones de hacer para las autoridades. Lo mismo sucede con los derechos sociales, que generan para la autoridad tanto obligaciones de abstención como obligaciones de realización, que requieren de actividades prestacionales en muchos casos. ${ }^{22}$
\end{abstract}

Ainda nos dizeres de Abramovich e Courtis, desta vez parafraseando van Hoof e Eide, um esquema interpretativo mais forte consiste na verificação de níveis de obrigações estatais, que caracteriza e identifica cada direito, além da sua descrição como direitos liberais ou sociais. Assim, vislumbram-se quatro níveis de obrigações estatais: respeito, proteção, garantia e promoção. A obrigação de respeitar se define pelo dever imposto ao Estado de não obstaculizar o acesso aos bens que formam o objeto do direito. A obrigação de proteção impede que terceiros ameacem o acesso a estes bens jurídicos. As obrigações de garantia asseguram que o titular do direito tenha acesso ao bem, ainda que não possa gozá-lo por si mesmo. Por sua vez, as obrigações de promoção determinam o dever de desenvolvimento de condições para que os titulares tenham acesso ao bem. ${ }^{23}$

Sem embargos, a colocação destas posições põe por terra alguns mitos que orbitam em torno dos Direitos Fundamentais. Todos os Direitos Fundamentais conjugam em seu bojo obrigações positivas e obrigações negativas, ou como cita Carbonell "pretensiones híbridas frente al poder" ${ }^{24}$, conforme já consignado alhures. De igual sorte não há direitos gratuitos ou direitos caros. Todos os direitos possuem um custo e exigem uma estrutura social que, na pior das hipóteses, proteja os indivíduos de possíveis violações tentadas por outrem. ${ }^{25}$

${ }^{22}$ CARBONELL, Miguel. La garantía de los derechos sociales en la teoría de Luigi Ferrajoli. p. 190.

23 ABRAMOVICH, Victor; COURTIS, Christian. Los derechos sociales como derechos exigibles. p. 28-29.

${ }^{24}$ CARBONELL, Miguel. La garantía de los derechos sociales en la teoría de Luigi Ferrajoli. p. 191.

${ }^{25}$ O debate acerca dos "custos" dos Direitos apresenta-se como questão central do Discurso Law and Economics. Grosso modo, esta escola vinculada umbilicalmente aos preceitos do neoliberalismo nega 
A liberdade de expressão, por exemplo ${ }^{26}$, não supõe somente a ausência de censura, exige também a construção de centros culturais e praças públicas, a subvenção de publicações, a concessão de espaços gratuitos em meios de comunicação e uma regulação geral que garanta um pluralismo informativo ${ }^{27}$. Do mesmo modo, o direito à saúde reclama além da destinação de verbas públicas para um sistema de atendimento universal e gratuito a abstenção de qualquer conduta comissiva/omissiva de ameaça à saúde (distribuição de medicamentos adulterados, a contaminação de recursos vitais).

Outra observação que merece destaque é a obrigação de progressividade e a proibição de regressividade dos Direitos Fundamentais, sejam eles liberais ou sociais. Como construção histórica que é, não seria lícito uma geração cingir as futuras da possibilidade de positivação de novos Direitos Fundamentais. É a procura por uma melhora contínua das condições de existência dos indivíduos que legitima este conjunto de direitos.

Esta mesma obrigação gera uma proibição de regressividade dos Direitos Fundamentais, algo como um efeito cliquet. Isto é, cada nova conquista impede que se retorne às condições primitivas. Tal proibição ganha relevo justamente nos períodos de crises, pois é nas dificuldades e na fragilização individual que mais se exige a intervenção estatal. Os Estados, em matéria de direitos sociais, em períodos de crises devem "priorizar la protección de los miembros más vulnerables de la sociedad." 28

Exposto isto, resta evidente que os principais argumentos contrapostos aos direitos econômicos, sociais e culturais como Direitos Fundamentais

qualquer forma de Direitos Fundamentais, exceto, claro o direito de propriedade e a liberdade de contratar. Além disso, procura inserir como critério determinante das decisões judiciais os custos e as externalidades econômicas. Desta forma, o direito assume posição de subserviência aos desígnios da economia de mercado. Indica-se, dentre muitas: POSNER, Richard A. Economic analysis of law. New York: Aspen, 2003; ROSA, Alexandre Morais da; LINHARES, José Manuel Aroso. Diálogos com a law \& economics. Rio de Janeiro: Lúmen Juris, 2009.

${ }^{26}$ Conforme Gerardo Pisarello: "El derecho de propiedad se garantiza no solo mediante la ausencia de interferencias estatales arbitrarias sino también mediante la creación de registros inmobiliarios o a través de la financiación estatal de tribunales, jueces y funcionarios que puedan asegurar el cumplimiento de los contratos. El derecho de voto comporta la puesta en marcha de una compleja infraestructura de personal y de material que en ningún caso carece de repercusiones económicas. Incluso el derecho a no ser torturado exige el mantenimiento de centros de detención adecuados y cuerpos policiales formados en principios garantistas. [...]. El derecho al trabajo no sólo comporta el acceso a un empleo digno sino también la prohibición de despidos ilegítimos. El derecho a una vivienda adecuada no sólo supone [...] la provisión de viviendas de protección oficial sino también el cumplimiento de otras obligaciones estatales no necesariamente costosas: desde el reconocimiento de seguridad jurídica en la tenencia o la interdicción de las cláusulas abusivas en los contratos de alquiler, hasta la derogación de preceptos discriminatorios en las leyes urbanísticas o la prohibición de desalojos arbitrarios." CARBONELL, Miguel. La garantía de los derechos sociales en la teoría de Luigi Ferrajoli. p. 191.

27 Na mesma linha de raciocínio recomenda-se a leitura de: CARBONELL, Miguel. La libertad de asociación en el constitucionalismo de América Latina. Revista Brasileira de Direitos Fundamentais \& Justiça - Revista do Programa de Pós-Graduação Mestrado e Doutorado em Direito da PUC/RS. Porto Alegre, a. IV, n. 12, p. 13-24, jul/set. 2010.

${ }^{28}$ CARBONELL, Miguel. La garantía de los derechos sociales en la teoría de Luigi Ferrajoli. p. 201.

Revista de Estudos Jurídicos, a. 15, n. 22, 2011 
materializa típico discurso sedicioso. Não são os Direitos Sociais meras declarações de boas intenções, compromissos políticos ou fraude tranqüilizadora $^{29}$, conforme registram Abramovich e Courtis ${ }^{30}$. Destarte, independente da postura que exijam, dos custos que gerem, os Direitos Fundamentais urgem de efetividade integral em benefício dos indivíduos, devendo o Estado observar a Constituição Federal como um documento constituinte e dirigente da Sociedade ${ }^{31}$. Neste contexto, espantados os "fantasmas", faz-se imperioso repensar a exigibilidade judicial dos Direitos Sociais em um Estado Democrático de Direito, afinal, ler a Constituição não erradica nem a fome, nem a sede.

\section{A EXIGIBILIDADE JUDICIAL}

A discussão acerca da exigibilidade social dos direitos sociais não é marcada por uma voz unívoca e pacífica. Há que se destacar que parte da doutrina, em especial aquela mais ligada aos clássicos direitos de liberdade e a um conceito de Estado mínimo levanta alguns argumentos contrários à judicialização destes novos direitos, como a inadequação da estrutura e da posição do Poder Judiciário para exigir o cumprimento de obrigações que importem em gastos do erário público; ou então a desigualdade que geraria o êxito de algumas ações individuais em que se faça exigível um direito, frente a situação de descumprimento de todos os demais casos idênticos e não pleiteados judicialmente; ou ainda a falta de instrumentos processuais concretos para remediar a violação de certas obrigações que tem como fonte direitos sociais ${ }^{32}$.

Contudo, não resta dúvida que a adoção de normas constitucionais ou de tratados internacionais que consagram direitos econômicos, sociais e culturais gera obrigações concretas ao Estado, inclusive exigíveis judicialmente, não podendo o Estado justificar o seu descumprimento alegando que não teve intenções de assumir uma obrigação jurídica, senão simplesmente de realizar uma declaração de boas intenções políticas ${ }^{33}$.

Ademais, entendendo-se o Judiciário como poder comprometido com os ideais constitucionais do Estado, em se constatando a inércia dos poderes públicos na realização de políticas e ações sociais determinadas

\footnotetext{
29 "Nessa linha, vem bem a propósito o dizer de Boaventura de Souza Santos, para quem esse Estado, também chamado de Estado Providência ou Social, foi a instituição política inventada nas sociedades capitalistas para compatibilizar as promessas da Modernidade com o desenvolvimento capitalista." STRECK, Lenio Luiz. Hermenêutica jurídica e(m) crise. Uma exploração hermenêutica da construção do direito. 8. ed. Porto Alegre: Livraria do Advogado, 2009, p. 22.

${ }^{30}$ ABRAMOVICH, Victor; COURTIS, Christian. Los derechos sociales como derechos exigibles. p. 19.

${ }^{31}$ CANOTILHO, Joaquim José Gomes. Constituição dirigente e vinculação do legislador. Coimbra: Coimbra, 2001.

${ }^{32}$ ABRAMOVICH, Victor; COURTIS, Christian. Los derechos sociales como derechos exigibles. p. 40.

${ }^{33}$ ABRAMOVICH, Victor; COURTIS, Christian. Los derechos sociales como derechos exigibles. p. 20 
constitucionalmente, "a via judiciária se apresenta como a via possível para a realização de direitos que estão previstos nas leis e na Constituição"34. Tanto é assim, verbaliza Pasold, que:

[...] não há sentido na criação e na existência continuada do Estado, senão na condição - inarredável - de instrumento em favor do Bem Comum ou Interesse Coletivo. Deve haver, por parte desta criatura da Sociedade, um compromisso com a sua criadora, sob pena de perda de substância e de razão de ser do ato criativo. ${ }^{35}$

A positivação de direitos fundamentais no texto constitucional torna o Estado devedor de uma série de prestações, que justamente por estarem inseridas no ordenamento jurídico, tornam-se judicialmente exigíveis. E, neste sentido, há que se reconhecer que o Poder Judiciário não pode manter-se inerte, ou mesmo afastado das questões sociais.

Conforme determina Carbonell, não resta dúvida que, sob o prisma jurídico, em sede de direitos sociais deve-se progredir para a judicialização dos mesmos. Para tanto, faz-se necessário a abertura de "vías jurisdiccionales" por meio das quais se possam sanar possíveis violações dos direitos sociais e a delimitação de um núcleo intangível dos direitos sociais, indisponíveis para o legislador e posto a disposição dos juízes, em especial, dos Tribunais Constitucionais, núcleo este que seja suficiente para "garantizar un mínimo vital indispensable del que pueda disfrutar cada persona".

A atuação jurisdicional deve ser comprometida com os ideais constitucionais, e proporcionar a realização de direitos que eventualmente são negligenciados pelos outros poderes. Se corrobora este entendimento com o reconhecimento de que na "falta de políticas públicas cumpridoras dos ditames do Estado Democrático de Direito, surge o Judiciário como instrumento para o resgate dos direitos não realizados" 37 .

Assim, entende-se que a celeuma acerca da possibilidade de se exigir judicialmente a concretização de direitos sociais resta superada pela discussão de como fazê-lo. O eixo do debate está em compatibilizar uma atuação jurisdicional democrática e garantista com a atual estrutura de poder, e como justificar decisões judiciais de cunho nitidamente de político/social.

O principal desafio da atuação jurisdicional nas questões sociais reside justamente na possibilidade de o Poder Judiciário inovar no mundo jurídico sem atravessar ilegitimamente as fronteiras dos demais poderes. Isso porque, via de

34 STRECK, Lenio Luiz. Hermenêutica Jurídica e(m) Crise. Uma exploração hermenêutica da construção do Direito. p. 53.

35 PASOLD, Cesar Luiz. Função social do Estado Contemporâneo. 3 ed. Florianópolis: OAB/SC Editora co-edição Editora Diploma Legal, 2003. p. 47.

${ }^{36}$ CARBONELL, Miguel. La garantia de los derechos sociales en la teoria de Luigi Ferrajoli. p. 189.

37 STRECK, Lenio Luiz. Hermenêutica Jurídica e(m) Crise. Uma exploração hermenêutica da construção do Direito. p. 53. 
regra, embates sociais chegam ao judiciário por inércia legislativa ou executiva - ausência de legislação específica sobre matérias de interesse popular e falta de políticas públicas voltadas para a área social.

Sem embargo, há que se ter a compreensão de que a clássica tripartição de funções do Estado ${ }^{38}$ deve ser vista não sob uma ótica reducionista ou mesmo negadora de direitos. Ao contrário, o ideal constitucional é que de forma livre, independente e harmônica, os três poderes possam maximizar os interesses de seus cidadãos. Caso contrário, é mister buscar alternativas para a realização de todas as gamas de direitos positivados constitucionalmente.

Autores das últimas décadas têm concordado no sentido de que no Estado Democrático de Direito ocorre um sensível deslocamento do centro de decisões do Legislativo e do Executivo para o plano da justiça constitucional. Enquanto que no Estado Liberal a primazia apontava com o Legislativo e no Estado Social a primazia ficava com o Executivo, no Estado Democrático de Direito o foco de tensão se volta para o Judiciário.

Através de instrumentos jurídicos como o controle de constitucionalidade e as ações coletivas, os interesses sociais não satisfeitos em outros órgãos e poderes bateram à porta do Judiciário em busca de uma resposta. Daí se afirmar que "inércias do Executivo e falta de atuação do Legislativo passam a poder ser supridas pelo Judiciário, justamente mediante a utilização dos mecanismos jurídicos previstos na constituição"39.

A não realização de políticas públicas previstas constitucionalmente traz um déficit de atuação que não pode mais ser aceito em um contexto de Estado Democrático de Direito. E é especialmente neste cenário de ausência de cumprimento constitucional que surge o Judiciário como instrumento para o resgate dos direitos não realizados. Para aqueles que não aceitam a atividade criativa do Judiciário, Cappelletti leciona que o debate acerca da possibilidade de o juiz atuar criativamente foi superada pela discussão acerca dos limites de atuação jurisdicional. Até porque:

[...] quando se fala dos juízes como criadores do direito, afirmase nada mais do que uma óbvia banalidade, um truísmo privado de significado: é natural que toda interpretação seja criativa". A verdadeira discussão se discorre "não sobre a alternativa criatividade-não criatividade, mas (como já disse) sobre o grau de criatividade e os modos, limites e legitimidade da criatividade judicial $^{40}$.

A atuação jurisdicional deve se pautar pela máxima eficácia constitucional. E, agindo assim, a princípio não há que se falar em interferência

${ }^{38}$ Esculpida em nossa Constituição Federal no artigo $2^{\text {o: }}$ "São Poderes da União, independentes e harmônicos entre si, o Legislativo, o Executivo e o Judiciário".

39 STRECK, Lenio Luiz. Hermenêutica Jurídica e(m) Crise. Uma exploração hermenêutica da construção do Direito. p. 52.

${ }^{40}$ CAPPELLETTI, Mauro. Juízes Legisladores. Tradução de Carlos Alberto Alvaro de Oliveira. Porto Alegre: Sérgio Antonio Fabris Editor, 1993, reimpressão 1999. p. 24-25. 
na atuação dos outros poderes, até porque a concretização dos direitos constitucionais deve ser o norte da atuação de toda a máquina estatal. E o juiz, como agente estatal que é, tem o dever de, se provocado, proporcionar a maior satisfação dos interesses sociais, ainda que para isso seja necessário "interferir na implementação de políticas públicas" ${ }^{\text {"41 }}$.

Some-se a isso que eventual inércia jurisdicional não passa impune neste contexto. Verdadeiras "guerras" são trazidas ao judiciário diariamente, e uma atuação displicente somente aumentará o índice de violência, seja nas cidades (meninos de rua, favelados), no campo (posseiros, sem-terra, índios) e contra grupos de minorias (crianças, mulheres, população negra, migrantes nordestinos). E as reais vítimas não são apenas as pessoas, mas a própria Democracia em si, o Estado Democrático de Direitos e os direitos fundamentais positivados constitucionalmente ${ }^{42}$.

Percebe-se então, "que o problema fundamental em relação aos direitos do homem, hoje, não é tanto o de justificá-los, mas o de protegê-los",43, e a previsão constitucional de direitos fundamentais sociais traz para a sociedade em geral o "direito de promover uma ação judicial contra os próprios órgãos do Estado", a exigir do ente público a efetiva realização dos compromissos firmados constitucionalmente. Assim, impossível se afastar a exigibilidade judicial de direitos sociais na construção de um Estado mais democrático e mais justo.

\section{JURISDIÇÃO DEMOCRÁTICA E ACESSO À JUSTIÇA COMO RESPOSTA JURISDICIONAL ÀS QUESTÕES SOCIAIS}

O regime democrático, estandarte constitucional assim como a tripartição de poderes, é dinâmico, e carecedor de implementação constante. As democracias da atualidade (inclusive a brasileira, por expressa disposição constitucional), não são compatíveis com a exclusão social, e a participação dos magistrados no processo democrático dá-se justamente tratando as partes com mais cidadania, e extraindo dos processos o máximo em garantia de direitos.

A atuação jurisdicional deve pautar-se por ideais democráticos e estar ajustada com a promoção da dignidade humana. O termo jurisdição democrática está ligado com o compromisso do poder judiciário em solucionar adequadamente os novos conflitos de ordem nitidamente sociais que chegam

\footnotetext{
${ }^{41}$ BRANDÃO, Paulo de Tarso. Atividade Jurisdicional, Políticas Públicas e Orçamento. In: OLIVEIRA NETO, Francisco José Rodrigues de; COUTINHO, Jacinto Nelson de Miranda; MEZZAROBA, Orides; BRANDÃO, Paulo de Tarso (Orgs.). Constituição e Estado Social - os obstáculos à concretização da Constituição. São Paulo: co-edição Coimbra Editora e Editora RT, 2008. p. 311.

${ }^{42}$ MULLER, Friedrich. Que grau de exclusão social ainda pode ser tolerado por um sistema democrático? In: PIOVESAN, Flávia (coord). Direitos humanos, globalização econômica e integração regional: desafios do direito constitucional internacional. São Paulo: Max Limonad, 2002. p. 573.

${ }^{43}$ BOBBIO, Norberto. A era dos direitos. Rio de Janeiro: Campus/Elsevier, 2004, p. 45.
} 
aos fóruns. São demandas que exprimem as tensões existentes na sociedade moderna, e que demandam julgamentos com viés nitidamente político e social.

Abreu leciona que neste contexto o juiz é levado a transcender suas funções tradicionais de adequar o fato à lei, assumindo também a atribuição de perquirir a realidade à luz dos valores e princípios constitucionais. "O Poder Judiciário passa a ser um ator que mantém sob sua guarda os direitos fundamentais, se cuja observância depende a legitimidade das leis" ${ }^{\text {"44. }}$.

Neste sentido, a Justiça não caminha mais isolada da política; ao contrário, o substrato volitivo do juiz deve estar em consonância com os anseios da sociedade e a realização dos direitos fundamentais. "A justiça moderna não pode ser apolítica, mesmo porque é inarredável o reconhecimento de que o poder judiciário é governo" ${ }^{45}$. Questões governamentais e "assuntos habilmente circunscritos à arena política estariam sendo objeto de decisões judiciais", tendo o Poder Judiciário se imposto aos demais poderes "como uma agência indutora de um efetivo checks and balances e da garantia da autonomia individual e cidadã"46.

$\mathrm{E}$, desta feita, reconhece-se que

[...]o constitucionalismo democrático conduz a uma crescente expansão do âmbito de intervenção do Judiciário sobre as decisões dos demais Poderes. Com isso, põe-se em evidência o novo papel do Poder Judiciário na vida coletiva, justificando o manejo da expressão 'democracia jurisdicional ${ }^{4748}$.

E dentro desta visão de Poder Judiciário democrático, mister um tratamento diferenciados das partes e dos bens jurídicos coletivos para o

44 ABREU, Pedro Manoel. Processo e Democracia. O processo jurisdicional como um locus da democracia participativa e da cidadania inclusiva no estado democrático de direito. São Paulo: Conceito Editorial, 2011.p. 266.

45 ABREU, Pedro Manoel. Processo e Democracia. O processo jurisdicional como um locus da democracia participativa e da cidadania inclusiva no estado democrático de direito. p. 272.

46 ABREU, Pedro Manoel. Processo e Democracia. O processo jurisdicional como um locus da democracia participativa e da cidadania inclusiva no estado democrático de direito. p. 270-271.

47 ABREU, Pedro Manoel. Processo e Democracia. O processo jurisdicional como um locus da democracia participativa e da cidadania inclusiva no estado democrático de direito. p. 266-267.

${ }^{48}$ Pedro Manoel Abreu também registra a procura pelo Judiciário para a solução de demandas com caráter nitidamente político, ao que chama de judicialização da política, uma vez se observa "um movimento crescente por parte da sociedade civil, das minorias políticas, das organizações sociais e do próprio cidadão, que recorrem ao Judiciário, 'contra leis, práticas da Administração ou omissões quanto a práticas que dela seria legítimo esperar, originárias tanto do Executivo quanto do Legislativo’. A judicialização desse movimento tem logrado eventualmente limitar a ação legislativa do Executivo, enquadrando a sua intervenção regulatória do mercado aos comandos da ordem racional-legal. Além disso, por meio de novos institutos processuais, como a ação popular e a ação civil pública, tem sido possível a defesa do cidadão contra o Estado e o poder econômico. O caráter afirmativo desse processo adquiriu tal relevância que hoje é plausível pensar em judicialização da política das relações sociais como dimensão da sociedade brasileira". ABREU, Pedro Manoel. Processo e Democracia. O processo jurisdicional como um locus da democracia participativa e da cidadania inclusiva no estado democrático de direito. p. 287. 
tratamento das partes voltada para a concretização da cidadania. A partir desta visão da democracia jurisdicional, ser parte no processo e buscar no judiciário a solução de seus interesses não significa mais ser apenas "sujeito do exercício legítimo do poder-violência; mas também, e antes do mais nada, ser levado a sério e ser tratado como norte, como fator legitimador da atuação do Estado" $" 49$.

Assim a superveniência da ação jurisdicional em questões de cunho político, é uma resposta constitucional para o problema social existente. O Judiciário é chamando a dar uma resposta diante de inércias inaceitáveis, transcorrendo daí uma legitimidade de atuação, uma vez que a "função jurisdicional transcende a modesta e subserviente atividade de ceder aos caprichos e à vontade do legislador (ou dos mandatários do poder)", pois, como poder criador, o Juiz não se constitui em um simples técnico que mecanicamente aplica o Direito. ${ }^{50}$

O reconhecimento da supremacia dos princípios jurídicos e o ideal de concretização de direitos fundamentais também conferiram maior legitimidade aos julgados, especialmente da Suprema Corte. A atuação jurisdicional ganha ainda mais relevância em demandas que envolvem o emprego de princípios jurídicos, "tipo de norma a cada dia mais em voga, que assume plena normatividade. A rigor, a apreensão da magnitude dos princípios jurídicos implica emergência de novo paradigma, redesenhando as possibilidades da função social" ${ }^{51}$.

Acrescente-se a isso que um efetivo acesso à justiça, transformando o Judiciário em um sistema no qual as pessoas podem reivindicar seus direitos e/ou resolver seus litígios, sistema esse acessível a todos o que produza resultados individual e socialmente justos ${ }^{52}$, aproximará a população das decisões que dizem respeito à sua esfera de interesses. Não resta dúvida que a aplicação do direito tem que contar, cada vez mais, com objetivos políticos, com fundamentações morais e com princípios ${ }^{53}$.

Há que se construir também a visão do processo judicial como um instrumento democrático para a busca de direitos, o que conferirá ao Judiciário um grau de legitimidade semelhante aos outros poderes. A partir de Guiddens, temos que:

\footnotetext{
${ }^{49}$ MULLER, Friedrich. Que grau de exclusão social ainda pode ser tolerado por um sistema democrático? In: PIOVESAN, Flávia (coord). Direitos humanos, globalização econômica e integração regional: desafios do direito constitucional internacional. São Paulo: Max Limonad, 2002. p. 573.

${ }^{50}$ WOLKMER, Antonio Carlos. Ideologia, Estado e Direito. 3 ed. São Paulo: Revista dos Tribunais, 2000. p. 179.

${ }^{51}$ NIEBUHR, Joel de Menezes. O novo regime constitucional da Medida Provisória. São Paulo: Dialética, 2001. p. 44.

${ }^{52}$ CAPPELLETTI, Mauro; GARTH, Bryant. Acesso à Justiça. Tradução de Ellen Gracie Northfleet. Porto Alegre: Sérgio Fabris Editora, 1988. p. 8.

${ }^{53}$ HABERMAS, Jürgen. Direito e Democracia: entre facticidade e validade, volume II. Tradução de Flávio Beno Siebeneichler. Rio de Janeiro Tempo Brasileiro, 1997. p. 229.
} 
[...] por um lado, a democracia é um instrumento para a representação de interesses. Por outro, é uma maneira de criar uma arena pública na qual assuntos controversos - em princípio - possam ser resolvidos, ou, pelo menos, abordados por meio de diálogo e não por formas preestabelecidas de $\operatorname{poder}^{54}$;

E este conceito de democracia deve ser trazido para o processo judicial. Assim, mediante a participação da sociedade civil organizada (via ONGs, associações, sindicatos, etc), a intervenção do Ministério Púbico, e sob um contraditório que possibilite a participação efetiva de todos aqueles que representem os interesses em jogo na lide, tem-se que o processo pode se transformar em um ambiente democrático para a solução de controvérsias ${ }^{55}$, mesmo as de cunho nitidamente político, e com a produção de decisões com alto grau de legitimidade, justamente por atender e garantir interesses sociais e/ou coletivos.

Ressalta-se, por fim, a lição de Alexy, no sentido de que as cortes judiciais interpretam as leis e as aplicam (ou não), ao caso concreto. A possibilidade de controle de constitucionalidade confere aos magistrados uma carga de soberania popular, pois ao decidir pela aplicação (ou não da lei) o juiz deve ter como norte o interesse dos cidadãos e/ou da sociedade como um todo. Nas palavras do próprio autor: "sobre a interpretação e ponderação dos direitos fundamentais, porém, decide em última instância - independente de como organizado - o tribunal constitucional e não o dador de leis parlamentar" [...] "não só o parlamento, mas também o tribunal constitucional representa o povo",

Desta feita, uma atuação democrática da magistratura se coaduna com os ideais constitucionais do Estado de Direito, e não há que se falar em obstáculos como invasão de competências ou falta de legitimidade. Ademais, um efetivo acesso à Justiça transformará o Poder Judiciário em um lócus de justiça social, através de processos que proporcionem a resposta que mais atenda aos interesses da sociedade.

\section{CONSIDERAÇÕES FINAIS}

Indubitavelmente, a história humana no mundo é marcada pelo clamor de melhores condições de vida. Assim como em tempos pretéritos, hodiernamente, uma grande parcela da população mundial resta excluída

${ }^{54}$ GIDDENS, Anthony. Para Além da Esquerda e da Direita - o futuro da política radical. Tradução de Alvaro Hattnher. São Paulo: Editora Unesp, 1996. p. 24.

${ }^{55}$ STAFFEN, Márcio Ricardo; CADEMARTORI, Daniela Mesquita Leutchuk de. A função democrática do princípio do contraditório no âmbito do processo administrativo disciplinar: aproximações entre Elio Fazzalari e Jürgen Habermas.

${ }^{56}$ ALEXY, Robert. Constitucionalismo discursivo. Tradução de Luís Afonse Heck. 2 ed. Porto Alegre: Livraria do Advogado Editora, 2008. p. 11. 
socialmente, sobrevivendo à margem de condições mínimas de dignidade, não tendo, desta forma, seus Direitos Fundamentais efetivados, ao contrário, não bastasse a constante omissão é forte, em termos práticos, o intuito negador de direitos sociais como direitos exigíveis.

Contudo, pensar em Direitos Fundamentais civis, políticos e sociais impõe a concordância que tais institutos jurídicos têm sua concepção vinculada a uma série de exigências formuladas perante o poder constituído. Exigências estas, muitas vezes banhadas em sangue humano. Logo, os Direitos Fundamentais são clamores dos indivíduos mais frágeis, juridicamente positivados após um progressivo processo de reivindicação. Não se resume, portanto, em concessões do Estado ou simplórias declarações de boas intenções.

Assim, sua eficácia transcende a natureza das obrigações que geram ou aos custos que agregam ao Estado. A própria matriz genética dos Direitos Fundamentais é suficiente para decretar a impotência desses argumentos. Neste sentido, o agente público não pode comportar-se como Pôncio Pilatos simplesmente lavar as mãos. O desleixo dos tradicionais executores dos Direitos Fundamentais não pode significar a inexigibilidade de tais direitos.

Cabe ao Poder Judiciário, ainda que sem adentrar na celeuma procedimentalistas versus substancialistas, dar efetividade aos Direitos Fundamentais, seja civis, políticos ou sociais, sob pena de reforçar um quadro de violência institucional, gerada pela estrutura do Estado. Ademais, acerca da exigibilidade plena dos direitos sociais é válido ressaltar que não existem, conforme demonstrado, diferenças estruturais que justifiquem distinções práticas tão exponenciais entre tais direitos.

Em um paradigma de Estado Democrático de Direito a exigibilidade judicial dos direitos sociais não pode, pela debilidade dos argumentos, ficar adstrita a discussão teórica sobre gerações de Direitos Fundamentais e a suposta prevalência que interna que comporta; não deve ficar vinculada aos tipos de obrigações impostas ao Estados; vai além dos custos decorrentes da sua efetivação. O desafio em sede de Poder Judiciário é facilitar o acesso à justiça, para que, pela via processual e à luz da Constituição Federal os interessados possam discutir democraticamente a satisfação dos direitos consagrados.

Ademais, é certo que inércias legislativas e executivas não podem mais ser aceitas nesta quadra da história, especialmente pela extensa positivação de direitos fundamentais de todas as gamas no texto constitucional. Deve-se superar a compreensão reducionista de que estas normas fundamentais foram introduzidas como mero programa de intenções, e dar-lhes normatividade plena, o que possibilita se exigir do Estado o seu devido comprimento, ainda que tal envolva a realização de prestações positivas.

Desta feita, a atividade jurisdicional ligada às questões sociais adquire legitimidade a partir da visão constitucional de que o processo judicial pode 
ser uma resposta democrática para a realização de direitos fundamentais negligenciados por outros órgãos e poderes. Daí a construção de um conceito de Jurisdição Democrática, baseada em uma atuação próxima da política e dos interesses da sociedade.

E esta atuação jurisdicional democrática, aliada a um efetivo acesso à justiça trará respostas úteis e necessárias socialmente, afastando de uma vez as críticas acerca do limites da atuação judicial, legitimando a utilização de instrumentos processais e jurídicos para a maximização de direitos e concretização de políticas voltadas para o social e transformando o Poder Judiciário em um "lócus" de justiça e cidadania.

\section{REFERÊNCIAS}

ABBAGNANO, Nicola. Dicionário de filosofia. 2. ed. Trad. Alfredo de Bosi. São Paulo: Mestre Jou, 1962.

ABRAMOVICH, Víctor; COURTIS, Christian. Los derechos sociales como derechos exigibles. Madrid: Trotta, 2002.

ABREU, Pedro Manoel. Processo e Democracia. O processo jurisdicional como um locus da democracia participativa e da cidadania inclusiva no estado democrático de direito. São Paulo: Conceito Editorial, 2011.

ALEXY, Robert. Constitucionalismo discursivo. Tradução de Luís Afonse Heck. 2 ed. Porto Alegre: Livraria do Advogado Editora, 2008.

BOBBIO, Norberto. A era dos direitos. Rio de Janeiro: Campus/Elsevier, 2004.

BRANDÃO, Paulo de Tarso. Atividade Jurisdicional, Políticas Públicas e Orçamento. In: OLIVEIRA NETO, Francisco José Rodrigues de; COUTINHO, Jacinto Nelson de Miranda; MEZZAROBA, Orides; BRANDÃO, Paulo de Tarso (Orgs.). Constituição e Estado Social - os obstáculos à concretização da Constituição. São Paulo: co-edição Coimbra Editora e Editora RT, 2008.

CANOTILHO, Joaquim José Gomes. Constituição dirigente e vinculação do legislador. Coimbra: Coimbra, 2001.

CAPPELLETTI, Mauro. Juízes Legisladores. Tradução de Carlos Alberto Alvaro de Oliveira. Porto Alegre: Sérgio Antonio Fabris Editor, 1993, reimpressão 1999.

; GARTH, Bryant. Acesso à Justiça. Tradução de Ellen Gracie Northfleet. Porto Alegre: Sérgio Fabris Editora, 1988.

CARBONELL, Miguel. La garantía de los derechos sociales en la teoría de Luigi Ferrajoli. In: ; SALAZAR, Pedro. Garantismo. Estudios sobre el pensamiento jurídico de Luigi Ferrajoli. Madrid: Trotta, 2005. 
. La libertad de asociación en el constitucionalismo de América Latina.

Revista Brasileira de Direitos Fundamentais \& Justiça - Revista do

Programa de Pós-Graduação Mestrado e Doutorado em Direito da PUC/RS.

Porto Alegre, a. IV, n. 12, p. 13-24, jul/set. 2010.

DELFIM NETO, Antonio. A criação de alternativas. Folha de São Paulo. São

Paulo, 21 nov. 1999.

FERRAJOLI, Luigi. Derecho y razón. Teoría del garantismo penal. 2. ed.

Trad. Perfecto Andrés Ibáñez. Madrid: Trotta, 2004.

GARCIA, Marcos Leite. Direitos fundamentais e transnacionalidade: um estudo preliminar. In: CRUZ, Paulo Márcio; STELZER, Joana. Direito e

transnacionalidade. Curitiba: Juruá, 2009.

. Efetividade dos Direitos Fundamentais: notas a partir da visão integral do conceito segundo Gregorio Peces-Barba. In: VALLE, Juliano Keller do; MARCELINO JR., Julio Cesar. Reflexões da Pós-Modernidade: Estado, Direito e Constituição. Florianópolis: Conceito Editorial, 2008.

GIDDENS, Anthony. Para Além da Esquerda e da Direita - o futuro da política radical. Tradução de Alvaro Hattnher. São Paulo: Editora Unesp, 1996.

HABERMAS, Jürgen. Direito e Democracia: entre facticidade e validade. volume II. Tradução de Flávio Beno Siebeneichler. Rio de Janeiro Tempo Brasileiro, 1997.

MULLER, Friedrich. Que grau de exclusão social ainda pode ser tolerado por um sistema democrático? In: PIOVESAN, Flávia (Coord). Direitos humanos, globalização econômica e integração regional: desafios do direito constitucional internacional. São Paulo: Max Limonad, 2002.

NIEBUHR, Joel de Menezes. O novo regime constitucional da Medida Provisória. São Paulo: Dialética, 2001.

PASOLD, Cesar Luiz. Função social do Estado Contemporâneo. 3 ed. Florianópolis: OAB/SC Editora co-edição Editora Diploma Legal, 2003.

PECES-BARBA MARTÍNEZ, Gregorio. La diacronia del fundamento y del concepto de los derechos: el tiempo de la historia. In: Curso de derechos fundamentales. Teoría general. Madrid: Universidad Carlos III de Madrid, 1995.

. Problemas generales. In: Curso de derechos fundamentales.

Teoría general. Madrid: Universidad Carlos III de Madrid: 1995.

PÉREZ LUÑO, Antonio-Enrique. La universalidad de los derechos humanos.

In: . La universalidad de los derechos humanos y Estado

constitucional. Bogotá: Universidad Externado de Colombia, 2002.

POSNER, Richard A. Economic analysis of law. New York: Aspen, 2003. 
ROSA, Alexandre Morais da; LINHARES, José Manuel Aroso. Diálogos com a law \& economics. Rio de Janeiro: Lúmen Juris, 2009.

STAFFEN, Márcio Ricardo; CADEMARTORI, Daniela Mesquita Leutchuk de. A função democrática do princípio do contraditório no âmbito do processo administrativo disciplinar: aproximações entre Elio Fazzalari e Jürgen Habermas. Revista Brasileira de Direitos Fundamentais \& Justiça - Revista do Programa de Pós-Graduação Mestrado e Doutorado em Direito da PUC/RS. Porto Alegre, a. IV, n. 12, p. 235-246, jul/set. 2010.

Entre a liberdade de contratar e a maximização de riquezas o direito do trabalho. Revista Eletrônica Investidura. Florianópolis, a. II, n. IX, p. 40-55, nov/dez. 2009.

STRECK, Lenio Luiz. Hermenêutica Jurídica e(m) Crise. Uma exploração hermenêutica da construção do Direito. 8 ed. ver. atual. Porto Alegre: Livraria do Advogado Editora, 2009.

TRINDADE, José Damião de Lima. A história social dos direitos humanos. São Paulo: Peirópolis, 2002.

WOLKMER, Antonio Carlos. Ideologia, Estado e Direito. 3 ed. São Paulo: Revista dos Tribunais, 2000. p. 179.

Recebido em 16-02-2011

Avaliado em 14-11-2011

Aprovado para publicação em 05-12-2011 